\title{
TratabiLIDADE dA ÁGUA DO RESERVATÓRIO DO GUARAPIRANGA: EFEITOS DA OZONIZAÇÃO SOBRE ALGUMAS VARIÁVEIS DE QUALIDADE DAS ÁGUAS
}

\section{TREATABILITY OF GUARAPIRANGA RESERVOIR WATER: EFFECTS OF OZONATION ON SOME WATER QUALITY VARIABLES}

\section{FREDERICO DE ALMEIDA LAGE FILHO}

M. E. pela EPUSP (1986), M.Sc. (1988) e Ph.D. (1992) em Engenharia Sanitária e Ambiental pela UC Berkeley.

Professor do Departamento de Engenharia Hidráulica e Sanitária da Escola Politécnica da Universidade de São Paulo

\section{EUVALDO RAMOS DE ANDRADE JÚNIOR}

Engenheiro Civil pela Escola Politécnica da USP. Mestre em Engenharia Hidráulica e Sanitária pela Escola Politécnica da Universidade de São Paulo

Recebido: 06/04/06 Aceito: 15/04/07

\section{RESUMO}

Ensaios de tratabilidade em bancada tendo cloreto férrico como coagulante foram conduzidos para avaliar efeitos da préozonização e da inter-ozonização sobre variáveis de qualidade de águas em diversas etapas de tratamento: demanda de cloro livre (DCL), absorbância de luz ultravioleta em 254 nm (abs UV254) e concentração de matéria orgânica (MO). Para águas decantadas, a ozonização favoreceu a remoção de $\mathrm{MO}$, mas não pareceu influenciar a redução da DCL, em relação aos ensaios sem ozonização. Para as águas filtradas, os ensaios com ozônio proporcionaram maiores remoçóes de $\mathrm{MO}$ e valores da relação DCL/MO do que os ensaios sem ozônio, porém estes últimos foram mais eficientes na redução da DCL. A ozonização da água bruta reduziu a concentração de $\mathrm{MO}$ e a abs UV254 mas não a DCL. A DCL imediata da água bruta foi estimada e pareceu não depender do tempo de contato.

\begin{abstract}
Bench scale treatability tests with ferric chloride coagulation were conducted to assess effects of pre-ozonation, inter-ozonation on water quality variables of water samples in several stages of treatment: free chlorine demand (FCD), absorbance of Ultra Violet light in the $254 \mathrm{~nm}$ wavelength (UV254 abs) and organic matter (OM) concentration. Regarding settling, ozonation favored OM removal but did not seem to influence FCD reduction, as compared with tests without ozonation. Regarding filtration, tests with ozonation led to higher OM removals and FCD/OM ratios than tests without ozonation. However, tests without ozonation were more efficient in reducing the FCD. Raw water ozonation decreased OM and UV254 abs values but not FCD values. The immediate FCD was obtained for raw water and it did not seem to depend on contact time.
\end{abstract}

PALAVRAS-CHAVE: Qualidade da água, ozônio, matéria orgânica, demanda de cloro.

\section{INTRODUÇÃO}

O Reservatório do Guarapiranga é um dos mais importantes para abastecimento da Região Metropolitana de São Paulo. Cerca de 3,2 milhões de habitantes são atendidos (SABESP, 2003). A monitoria constante de parâmetros de qualidade da água bruta e tratada é essencial para o controle de qualidade da água potabilizada fornecida à população. Cada parâmetro tem sua relevância para o tratamento e é importante avaliar possíveis conexóes entre eles. Andrade Jr. (2004) conduziu ensaios de tratabilidade com água bruta do Guarapiranga, coletada junto à captação do reservatório e antes da pré-cloração. O autor determinou turbidez, cor aparente, pH, absorbância em luz ultravioleta em $254 \mathrm{~nm}$, (abs UV 254), concentração de matéria orgânica $(\mathrm{MO})$ e demanda de cloro livre (DCL) para amostras de água bruta e tratada, em diversos estágios de tratamento, a partir de extensas séries de ensaios em escala de bancada. Um ponto focal aos ensaios foi a aplicação de ozônio na água bruta (ou pré-ozonização) e na água decantada (ou inter-ozonização). Procurou-se avaliar se era possível reduzir adequadamente a concentração de $\mathrm{MO}$ e o valor da DCL da água tratada. Procurou-se também avaliar a contribuição da pré-ozonização e da inter-ozoniza- ção para tais reduçôes. Os resultados das determinações de turbidez, abs UV 254, concentrações de matéria orgânica natural (MON) e valores de DCL foram pareados graficamente, de modo a avaliar possíveis conexôes entre elas e os efeitos da aplicação de ozônio nas águas brutas e decantadas na tratabilidade das águas eutrofizadas do Guarapiranga. Sendo assim, os objetivos deste trabalho foram de:

(1) Avaliar possíveis relações e conexões entre as variáveis selecionadas.

(2) Avaliar efeitos da ozonização na tratabilidade das águas brutas do Reservatório do Guarapiranga, em termos de reduções de turbidez, abs UV 254, concentraçôes de MO e DCL. 


\section{MATERIAL E MÉTODOS}

Na Figura 1 é mostrado esquematicamente o modo de obtenção dos tipos de amostras (indicadas por siglas - vide Tabela 1) de água a partir dos ensaios de tratabilidade em escala de bancada.

$\mathrm{Na}$ Figura 1 são mostradas os 3 tipos de ensaios (a, b, c) executadas com a água bruta $(\mathrm{ab})$ :

(a) testes de jarros (jar tests) para obtenção de água decantada; a partir daí, 2 ramificaçôes: (a1) parte da água decantada era ozonizada e depois filtrada; (a2) parte da água decantada era filtrada. bruta.

(b) ensaios de filtração da água

(c) pré-ozonização da água bruta, seguida por 2 ramificações: (c1) testes de jarros (jar tests) para obtenção de água decantada, que era então filtrada; (c2) filtração da água bruta pré-ozonizada.

Os tipos de águas obtidos nos ensaios de tratabilidade esquematizados na Figura 1 estão na Tabela 1.

\section{Sistema de ozonização em escala de bancada}

Foi constituído de uma coluna de ozonização em batelada de acrílico, com $1,8 \mathrm{~m}$ de altura útil e $10 \mathrm{~cm}$ de diâmetro, alimentada por um difusor de fundo de bolhas de cerca de $1 \mathrm{~mm}$. $\mathrm{O}$ ozônio era produzido por gerador UTK-05B da Unitek, operando com oxigênio puro fornecido pela White Martins Gases Industriais SA, com capacidade de $4 \mathrm{~g} \mathrm{O}_{3} / \mathrm{h}$. A coluna possui três torneiras de amostragem igualmente espaçadas ao longo da altura para amostragem e subseqüente determinação de concentração de ozônio na fase líquida. As concentrações de ozônio na fase líquida foram determinadas via espectrofotômetro $\mathrm{HACH}$ modelo DR 2010 e ampolas de reagente indigo (HACH Corporation) conforme metodologia do Standard Methods for The Examination of Water and Wastewater (APHA/WEF/AWWA, 1996).

\section{Testes de jarros (Jar Testes)}

Foi empregado um equipamento com doze jarros de 2 litros cada, pás planas de rotação controladas por um único motor e indicador de rotação (fabricante: Ética LTDA, Cotia, SP). As condiçôes ótimas para os testes de jarros foram: (a) gradientes médios de velocidades de $600 \mathrm{~s}^{-1}$ e $20 \mathrm{~s}^{-1}$ para coagulação e floculação, respectivamente; (b) dosagens ótimas de coagulantes associadas a faixas estreitas de $\mathrm{pH}$ de coagulação $(28 \pm 3 \mathrm{mg} / \mathrm{L}$ de cloreto férrico hexahidratado em pH 6,0 \pm 0,2); (c) tempos de coagulação, floculação e decantação foram 1, 20 e 40 minutos.

\section{Filtração de amostras}

A filtração em bancada foi executada por meio de filtração a vácuo utilizando filtro de papel modelo AP20 (Millipore Corporation, USA) com malha de 1,4 a 1,5 microns e $47 \mathrm{~mm}$ de diâmetro, em malha de microfibra de vidro.

\section{Determinações analíticas}

A determinação de turbidez foi via turbidímetro HACH modelo $2100 \mathrm{~N}$; a da cor aparente foi via espectrofo- tômetro HACH modelo DR2010. A determinação do $\mathrm{pH}$ das amostras foi por meio de pHmetro Orion-Jundilab modelo 720A e a determinação da absorbância de luz UV em 254 nm, que é uma avaliação indireta substituta para o teor de matéria orgânica, foi por meio de espectrofotômetro da Shimadzu, modelo UV-1203.

A demanda de cloro foi determinada a partir de uma solução-padrão de hipoclorito de sódio, preparada antes de cada bateria de ensaios e mantida tampada em erlenmeyer, refrigerada e no escuro, sendo re-padronizada antes de cada série de testes. Amostras de água eram coletadas em erlenmeyers, recebiam dosagem de cloro livre, eram tampados e refrigerados. As dosagens foram: cerca de $2,0 \mathrm{mg} / \mathrm{L}$ para água filtrada, de 3,0 a $4,0 \mathrm{mg} / \mathrm{L}$ para água decantada e cerca de $6,0 \mathrm{mg} / \mathrm{L}$ para água bruta. Perdas de cloro por volatilização e falta de controle sobre reações de consumo de cloro livre durante a aplicação das dosagens podem explicar as variações verificadas nas determinaçóes das dosagens iniciais por tipo de água. A obtenção da concentração de cloro livre residual foi pela aplicação de reagente $\mathrm{HACH}$ em cubeta de $20 \mathrm{~mL}$ com cada amostra. A cubeta era então secada e colocada em espectrofotômetro marca HACH, modelo DR 2010.

A determinação do teor de matéria orgânica $(\mathrm{MO})$ em amostras de água bruta e tratadas foi pelo método do consumo de oxigênio a partir de oxidação da amostra em permanganato de potássio em meio ácido (conforme a NBR 10739/89 - Determinação de Oxigênio Consumido - Método do Permanganato de Potássio).

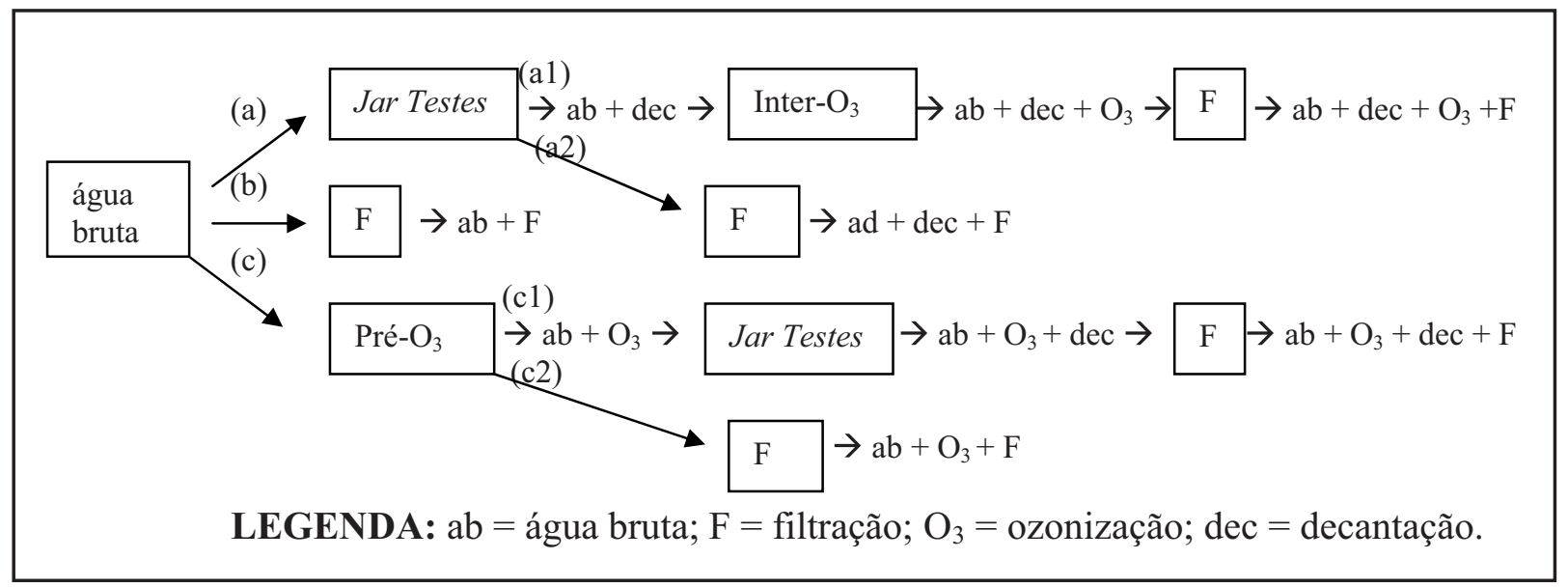

Figura I - Tipos de amostras de água obtidas dos ensaios de tratabilidade 
Tabela I - Tipos de águas obtidos nos ensaios

\begin{tabular}{cc}
\hline Tipo de água & Descrição do processo de obtenção \\
\hline $\mathrm{ab}$ & Água bruta \\
$\mathrm{ab}+\mathrm{O}_{3}$ & Água bruta seguida de pré-ozonização \\
$\mathrm{ab}+\mathrm{O}_{3}+\mathrm{dec}$ & Água decantada a partir de água bruta pré-ozonizada \\
$\mathrm{ab}+\mathrm{dec}$ & Águadecantada a partir da água bruta \\
$\mathrm{ab}+\mathrm{dec}+\mathrm{O}_{3}$ & Água decantada a partir de a. bruta, seguida por inter-ozonização \\
$\mathrm{ab}+\mathrm{F}$ & Água bruta seguida por filtração direta \\
$\mathrm{ab}+\mathrm{O}_{3}+\mathrm{F}$ & Água bruta pré-ozonizada seguida por filtração direta \\
$\mathrm{ab}+\mathrm{dec}+\mathrm{F}$ & Água bruta decantada seguida por filtração \\
$\mathrm{ab}+\mathrm{O}_{3}+\mathrm{dec}+\mathrm{F}$ & Água bruta pré-ozonizada, seguida por decantação e filtração \\
$\mathrm{ab}+\mathrm{dec}+\mathrm{O}_{3}+\mathrm{F}$ & Água bruta decantada, seguida por inter-ozonização e filtração \\
\hline
\end{tabular}

\section{RESULTADOS E DISCUSSÂOO}

A Tabela 2 é um sumário dos resultados obtidos nos ensaios de tratabilida-de. Foram executados três grupos de ensaios. Os resultados por grupo estão separados por linhas horizontais. As três primeiras colunas apresentam, respectivamente, a nomenclatura das amostras (de acordo com símbolos definidos na Figura 1 e Tabela 1), os resultados de turbidez e cor aparente. Para as demais colunas: "Tc" é o tempo de contato na ozonização, "C" o valor médio da concentração de ozônio dissolvido no líquido. "Abs UV 254 nm" e "MO" foram definidos na introdução. As duas últimas colunas apresentam a dosagem de cloro livre e a demanda de cloro livre com duas horas de tempo de contato. Foram também obtidos valores de DCL com 10 minutos de tempo de contato, que não estão na Tabela 2. Os residuais de cloro livre para os tempos de contato de 2 horas e de 10 minutos estão na Figura 8. O tempo de contato do ozônio variou de 3 a 8 minutos, exceto um ensaio (1,5 minutos) e o produto $\mathrm{C} \times \mathrm{T}$ c variou de $2,7 \mathrm{a}$ $11,4 \mathrm{mg} \times \mathrm{min} / \mathrm{L}$ para a pré-ozonização e de 4,7 a $10,6 \mathrm{mg} \times \mathrm{min} / \mathrm{L}$ para a inter-ozonização (exceto um ensaio, com $1,0 \mathrm{mg} \mathrm{x} \mathrm{min/L).} \mathrm{As} \mathrm{faixas} \mathrm{de} \mathrm{tempos}$ de contato e concentraçôes de ozônio na fase líquida utilizadas foram escolhidos com base em estudos de tratabilidade de águas brutas com características físico-químicas similares (Camp, Dresser \& McKee, 1995a;1995b; West e Lage Filho, 1994).

A partir dos resultados de concentrações de matéria orgânica e demanda de cloro livre de duas horas apresentados na Tabela 2, foram obtidos os valores médios de remoção (ou aumento) dessas variáveis por tipo de tratamento praticado, em relação aos valores obtidos para a água bruta do Guarapiranga. As médias globais dos três grupos de ensaios e os desvios-padrōes das mesmas estão na Tabela 3.

Remoção de MO por tipo de tratamento: de acordo com a Tabela 3 , a decantação de água pré-ozonizada proporcionou remoção média de $77 \%$ ou $23 \%$ a mais que a decantação da água bruta. A inter-ozonização de água decantada sem pré-ozonização proporcionou redução de $66 \%$. A decantação de água bruta sem ozonização levou à redução média de $54 \%$. A filtração de água decantada pré-ozonizada, inter-ozonizada e de água decantada sem ozonização conduziram a reduções médias de 82,70 e $51 \%$, respectivamente. A filtração da água bruta pré-ozonizada e a da água bruta sem ozonização proporcionaram remoções médias de 50 e $26 \%$, respectivamente.

Redução da DCL de 2 horas por tipo de tratamento: de acordo com as médias globais na Tabela 3, as reduções médias proporcionadas pela decantação da água bruta, decantação da água bruta pré-ozonizada e pela inter-ozonização da água decantada obtida sem préozonização foram de 34,33 e $35 \%$, respectivamente. A redução da DCL pela filtração da água decantada sem pré-ozonização foi de $73 \%$, sendo $21 \%$ a mais que a redução proporcionada pela filtração de água decantada inter-ozonizada e pela filtração de água decantada com pré-ozonização da água bruta. A redução proporcionada pela filtração da água bruta, com ou sem pré-ozonização, foi de $59 \%$.

O controle das condiçóes de ensaio, particularmente de $\mathrm{pH}$, possibilita a obtenção de resultados de redução de $\mathrm{MO}$ e DCL melhores do que os que são obtidos em Estações de Tratamento em escala real, que foram o objeto de estudo por Camp, Dresser \& McKee (1994; 1995b). Os estudos por West e Lage Filho (1994) e por Camp, Dresser \& McKee (1995a, 1995b) não investigaram efeitos da aplicação de ozônio na água bruta ou decantada sobre a demanda de cloro da água filtrada. $\mathrm{O}$ único aumento médio verificado (de $5 \%$ ) foi na DCL da água pré-ozonizada, em relação à DCL da água bruta correspondente.

A presença de matéria orgânica natural (MON) na água bruta é indesejável sob o ponto de vista de tratabilidade, devido à uma variedade de motivos: desde a presença de cor aparente indesejável, até o aumento da quantidade de sítios de absorção para substâncias tóxicas e/ou mutagênicas na água. A MON também será adsorvida por partículas inorgânicas presentes na água bruta, desse modo reduzindo as características de sedimentabilidade das mesmas. A presença de elevados níveis de certos constituintes de MON requerem maiores doses de coagulante para a desestabilização de partículas com subseqüente remoção nos tanques de sedimentação e/ou filtros (EPA, 1999). A matéria orgânica possui em sua composição substâncias precursoras de subprodutos da desinfecção tais como os compostos orgânicos clorados (ácidos haloacéticos e trialometanos), que são gerados pela reação com cloro. A matéria orgânica, em termos de carbono orgânico total (COT), é um dos principais responsáveis pela demanda de cloro na água (Becker e O' Melia, 1996).

A determinação da absorbância em luz UV254 nm é uma alternativa rápida de obtenção de uma estimativa do conteúdo de matéria orgânica da amostras de água bruta ou tratada (Penitsky, 2003). Ainda segundo o au- 
Tabela 2 - Resumo dos resultados dos ensaios de tratabilidade

\begin{tabular}{|c|c|c|c|c|c|c|c|c|c|}
\hline $\begin{array}{c}\text { Tipo de } \\
\text { amostra de água }\end{array}$ & $\begin{array}{l}\text { turb. } \\
\text { (UNT) }\end{array}$ & $\begin{array}{l}\text { cor ap. } \\
\text { (Pt-Co) }\end{array}$ & $\begin{array}{c}\mathrm{Tc} \\
(\mathrm{min})\end{array}$ & $\begin{array}{c}\mathrm{C} \times \mathrm{xc}_{\mathrm{c}} \\
(\operatorname{mgxmin} / \mathrm{L})\end{array}$ & $\begin{array}{c}\text { abs UV } \\
254\end{array}$ & $\begin{array}{c}\mathrm{MO} \\
\left(\mathrm{mg} \mathrm{O}_{2} / \mathrm{L}\right)\end{array}$ & $\begin{array}{l}\mathrm{pH} \\
(--)\end{array}$ & $\begin{array}{c}{\left[\mathrm{Cl}_{2}\right] \text { inicial }} \\
(\mathrm{mg} / \mathrm{L})\end{array}$ & $\begin{array}{l}\text { Dem. } 2 \mathrm{hr} \\
(\mathrm{mg} \mathrm{Cl} / \mathrm{L})\end{array}$ \\
\hline $\mathrm{ab}$ & 4,26 & 53 & - & - & 0,091 & 2,9 & 6,9 & 6,4 & 4,10 \\
\hline $\mathrm{ab}+\mathrm{O}_{3}$ & 3,00 & 25 & 5,3 & 7,0 & 0,024 & 2,6 & 6,6 & 6,4 & 3,68 \\
\hline$a b+d e c$ & 0,33 & 4 & - & - & 0,027 & 1,4 & 6,4 & 3,3 & 2,77 \\
\hline $\mathrm{ab}+\mathrm{dec}+\mathrm{O}_{3}$ & 0,70 & 6 & 7,0 & 10,6 & 0,007 & 1,0 & 6,4 & 3,2 & 2,14 \\
\hline$a b+\operatorname{dec}$ & 0,30 & 7 & - & - & 0,028 & 1,3 & 5,9 & 4,3 & 2,18 \\
\hline$a b+d e c$ & 0,26 & 5 & - & - & 0,032 & 1,7 & 6,1 & 3,2 & 1,27 \\
\hline $\mathrm{ab}+\mathrm{dec}+\mathrm{O}_{3}$ & 0,44 & 6 & 6,0 & 9,8 & 0,015 & 1,0 & 6,1 & 3,3 & 1,99 \\
\hline $\mathrm{ab}+\mathrm{dec}+\mathrm{O}_{3}$ & 0,70 & 13 & 8,0 & 11,4 & 0,015 & - & 6,0 & 3,2 & 2,15 \\
\hline $\mathrm{ab}+\mathrm{O}_{3}$ & 2,62 & 26 & 5,0 & 6,7 & 0,055 & 1,4 & - & 6,4 & 3,37 \\
\hline $\mathrm{ab}+\mathrm{O}_{3}$ & 2,93 & 28 & 5,5 & 7,9 & 0,045 & 2,8 & - & 6,4 & 4,98 \\
\hline $\mathrm{ab}+\mathrm{O}_{3}+\mathrm{dec}$ & 0,26 & 6 & 5,3 & 7,0 & 0,016 & 0,9 & 6,4 & 3,3 & 1,40 \\
\hline$a b+d e c$ & 0,29 & 9 & - & - & 0,033 & 1,3 & 6,0 & 3,3 & 1,46 \\
\hline$a b+F$ & 0,195 & 9 & - & - & 0,083 & 2,0 & - & 2,0 & 1,30 \\
\hline $\mathrm{ab}+\mathrm{O}_{3}+\mathrm{F}$ & 0,210 & 3 & 5,3 & 7,0 & 0,037 & 1,4 & - & 2,1 & 0,82 \\
\hline$a b+\operatorname{dec}+F$ & 0,177 & 3 & - & - & 0,046 & 1,0 & - & 2,1 & 1,06 \\
\hline $\mathrm{ab}+\mathrm{dec}+\mathrm{O}_{3}+\mathrm{F}$ & 0,177 & 2 & 7,0 & 10,6 & 0,020 & 0,8 & - & 2,0 & 1,90 \\
\hline $\mathrm{ab}+\operatorname{dec}+\mathrm{O}_{3}+\mathrm{F}$ & 0,200 & 2 & 7,0 & 10,6 & 0,020 & - & - & 2,0 & 1,81 \\
\hline $\mathrm{ab}$ & 3,40 & 58 & - & - & 0,112 & 4,0 & 6,8 & 6,0 & 2,58 \\
\hline $\mathrm{ab}+\mathrm{O}_{3}$ & 2,65 & 23 & 5,9 & 2,7 & 0,036 & 1,9 & - & 6,0 & 3,08 \\
\hline $\mathrm{ab}+\mathrm{O}_{3}$ & 1,23 & 23 & 8,0 & 4,5 & 0,046 & 1,7 & 6,8 & 6,0 & 2,22 \\
\hline $\mathrm{ab}+\mathrm{O}_{3}$ & 1,80 & 31 & 4,0 & 4,5 & 0,044 & 2,0 & - & 6,0 & 2,62 \\
\hline$a b+d e c$ & 0,63 & 19 & - & - & 0,035 & 1,9 & - & 4,0 & 1,86 \\
\hline$a b+d e c$ & 0,44 & 16 & - & - & 0,045 & 1,4 & 6,7 & 4,0 & 2,22 \\
\hline$a b+d e c$ & 0,48 & 18 & - & - & 0,047 & 2,6 & 6,6 & 4,0 & 1,94 \\
\hline $\mathrm{ab}+\mathrm{dec}+\mathrm{O}_{3}$ & 0,93 & 20 & 5,0 & 4,7 & 0,026 & 1,2 & 6,6 & 4,0 & 2,12 \\
\hline $\mathrm{ab}+\mathrm{dec}+\mathrm{O}_{3}$ & 0,48 & 16 & 1,5 & 1,0 & 0,016 & 1,1 & - & 4,2 & 1,68 \\
\hline $\mathrm{ab}+\mathrm{dec}+\mathrm{O}_{3}$ & 0,75 & 19 & 3,0 & 5,0 & 0,034 & 1,3 & 6,8 & 4,0 & 2,24 \\
\hline $\mathrm{ab}+\mathrm{O}_{3}+\mathrm{dec}$ & 0,40 & 16 & 5,9 & 2,7 & 0,007 & 1,2 & - & 6,0 & 2,25 \\
\hline $\mathrm{ab}+\mathrm{O}_{3}+\mathrm{dec}$ & 0,44 & 17 & 5,9 & 2,7 & 0,023 & 1,2 & 6,6 & 6,0 & 1,80 \\
\hline$a b+d e c+F$ & 0,380 & 12 & - & - & 0,047 & 1,5 & 7,2 & 2,1 & 1,06 \\
\hline $\mathrm{ab}+\mathrm{dec}+\mathrm{O}_{3}+\mathrm{F}$ & 0,330 & 8 & 3,0 & 5,0 & 0,011 & 1,0 & 6,9 & 2,1 & 1,21 \\
\hline $\mathrm{ab}+\mathrm{O}_{3}+\mathrm{dec}+\mathrm{F}$ & 0,320 & 9 & 5,9 & 2,7 & 0,013 & 1,0 & 7,0 & 2,1 & 0,82 \\
\hline $\mathrm{ab}+\operatorname{dec}+\mathrm{O}_{3}+\mathrm{F}$ & 0,310 & 7 & 5,0 & 4,7 & 0,007 & 1,1 & 7,2 & 2,1 & 1,25 \\
\hline $\mathrm{ab}$ & 3,00 & 30 & - & - & 0,131 & 3,1 & 7,3 & 6,0 & 3,10 \\
\hline $\mathrm{ab}+\mathrm{O}_{3}$ & 1,21 & 6 & 4,0 & 4,3 & 0,034 & 1,5 & - & 6,0 & 4,16 \\
\hline $\mathrm{ab}+\mathrm{O}_{3}+\mathrm{dec}$ & 0,55 & 1 & 4,0 & 4,3 & 0,015 & 0,4 & - & 4,0 & 2,14 \\
\hline$a b+d e c$ & 0,51 & 1 & - & - & 0,039 & 1,1 & - & 4,0 & 2,44 \\
\hline $\mathrm{ab}+\mathrm{dec}+\mathrm{O}_{3}$ & - & - & 4,0 & 5,5 & 0,023 & 1,3 & - & 4,0 & 2,03 \\
\hline$a b+d e c$ & 0,51 & 1 & - & - & 0,039 & 1,1 & - & 4,0 & 3,05 \\
\hline $\mathrm{ab}+\mathrm{O}_{3}+\mathrm{dec}$ & 0,55 & 1 & 4,0 & 4,3 & 0,015 & 0,4 & - & 4,0 & 2,30 \\
\hline$a b+\operatorname{dec}+F$ & 0,30 & 1 & - & - & 0,030 & 2,3 & - & 2,2 & 0,44 \\
\hline $\mathrm{ab}+\mathrm{dec}+\mathrm{O}_{3}+\mathrm{F}$ & 0,30 & 1 & 4,0 & 5,5 & 0,013 & 1,2 & - & 2,0 & 1,82 \\
\hline $\mathrm{ab}+\mathrm{O}_{3}+\mathrm{dec}+\mathrm{F}$ & 0,25 & 1 & 4,0 & 4,3 & 0,009 & 0,5 & - & 2,0 & 1,83 \\
\hline $\mathrm{ab}+\mathrm{O}_{2}+\mathrm{dec}+\mathrm{F}$ & 0,25 & 1 & 4,0 & 4,3 & 0,010 & 0,4 & - & 2,0 & 1,62 \\
\hline
\end{tabular}


Tabela 3 - Remoções da concentração de $\mathrm{MO}$ e da demanda de cloro livre para os vários tipos de tratamentos, em relação aos valores da água bruta

\begin{tabular}{ccc}
\hline $\begin{array}{c}\text { Tipo de tratamento } \\
(\text { definições na Tabela 1) }\end{array}$ & $\begin{array}{c}\text { Redução média da } \\
\text { concentração de MO (\%) }\end{array}$ & $\begin{array}{c}\text { Redução média da DCL } \\
\text { de } 2 \text { horas }(\%)\end{array}$ \\
\hline $\mathrm{ab}+\mathrm{O}_{3}$ & $38 \pm 21$ & $-5 \pm 19$ \\
$\mathrm{ab}+\mathrm{dec}$ & $54 \pm 11$ & $34 \pm 22$ \\
$\mathrm{ab}+\mathrm{O}_{3}+\mathrm{dec}$ & $77 \pm 10$ & $33 \pm 20$ \\
$\mathrm{ab}+\mathrm{dec}+\mathrm{O}_{3}$ & $66 \pm 5$ & $35 \pm 15$ \\
$\mathrm{ab}+\mathrm{F}$ & $26 \pm 5$ & $59 \pm 13$ \\
$\mathrm{ab}+\mathrm{O}_{3}+\mathrm{F}$ & $50 \pm 2$ & $59 \pm 30$ \\
$\mathrm{ab}+\mathrm{dec}+\mathrm{F}$ & $51 \pm 22$ & $73 \pm 14$ \\
$\mathrm{ab}+\mathrm{O}_{3}+\mathrm{dec}+\mathrm{F}$ & $82 \pm 6$ & $52 \pm 14$ \\
$\mathrm{ab}+\mathrm{dec}+\mathrm{O}_{2}+\mathrm{F}$ & $70 \pm 6$ & $52 \pm 6$ \\
\hline
\end{tabular}

tor, "embora a relação numérica entre abs UV 254 e Carbono Orgânico Total (COT) é única para cada água bruta, uma mudança no teor de carbono orgânico sempre pode ser detectado, em termos de absorbância de luz UV. Isto torna a determinação da abs UV254 adequada para monitorar mudanças na concentração de MON". Segundo Andrade Jr. (2004), a determinação da absorbância UV254 tem por base a capacidade da matéria orgânica de absorver luz UV. A oxidação da matéria orgânica de origem húmica pelo ozônio reduz o valor da absorbância UV 254. No entanto, segundo Owen et al (1994), tal redução não é necessariamente acompanhada por redução correspondente do teor de carbono orgânico dissolvido, porque a ozonização promove predominantemente a transformação de substâncias húmicas em não-húmicas, sendo a parcela húmica a responsável pela absorção de luz UV, devido às ligaçốes químicas insaturadas ou estruturas aromáticas.

A remoção de COT em Estaçōes de Tratamento (ETA) é influenciada pelo tipo de coagulante, $\mathrm{pH}$ de coagulação-floculação e diversas características da água, particularmente carbono orgânico total e dissolvido (COT, COD) e alcalinidade. A água bruta do Guarapiranga contem COT acima de $10 \mathrm{mg} / \mathrm{L}$ e alcalinidade menor que $60 \mathrm{mg} \mathrm{CaCO}_{3} / \mathrm{L}$; de acordo com essas informaçôes, a remoção de COT por meio de coagulação aprimorada em $\mathrm{pH}$ em torno de 5,5 e com sal de ferro como coagulante pode chegar a $50 \%$ na ETA (Camp, Dresser \& McKee, 1994). Penitsky (2003) considerou como parâmetro indicador da eficiência de remoção de COT a variável "absorbância específica de luz ultravioleta ou SUVA, definida como sendo igual a (100 x abs UV254)/COD. Para a água bruta do Guarapiranga, pode-se assumir valor médio de COT de $8 \mathrm{mg} / \mathrm{L}$ e que o carbono orgânico dissolvido representa cerca de $80 \%$ do COT. Desse modo, e para valor de absorbância UV254 de amostra agitada de água bruta igual a 0,14 , foi obtido um valor de SUVA $\cong 2,2 \mathrm{~L} / \mathrm{mg}$. Segundo o autor, SUVA na faixa 2 a $4 \mathrm{~L} / \mathrm{mg}$ indica que os teores de matéria orgânica natural influenciam a coagulação, e que a eficiência de remoção de COD da água bruta na Estação de Tratamento deverá estar na faixa 25 a $50 \%$ com a utilização de sulfato de alumínio ou um pouco acima disso para a utilização de cloreto férrico como coagulante. Ferreira Filho e Marchetto (2006) estudaram a tratabilidade da água do reservatório do rio Grande e concluíram que a dosagem ótima de sulfato férrico para remoção de turbidez e cor aparente tendeu a ser inferior à dosagem ótima para maximizar remoção de carbono orgânico dissolvido (COD). Sendo assim, é a concentração de COD e não a turbidez ou cor aparente que estabelece a dose ótima de coagulante. Segundo Singer e Harrington (1993), os teores de COD representam tipicamente cerca de $80 \%$ dos teores de COT.

Manuais de qualidade e tratamento de águas de abastecimento editados por Agências e Organizações de alto prestígio (AWWA, 1999; EPA, 1999) afirmam que a ozonização da água bruta (ou pré-ozonização) pode atuar eficazmente como auxiliar de coagulação e floculação, contribuindo para melhorar a eficiência destas operações unitárias. Extensos estudos de tratabilidade (West e Lage Filho, 1994; Camp, Dresser \& McKee, 1995a;1995b; Andrade Jr., 2004) verificaram tais afirmações.

De acordo com Francisco Jr. e Orth (1988), a ozonização pode promover uma maior remoção de ma- téria orgânica durante os processos de coagulação, floculação e decantação, graças à atuação de um mecanismo múltiplo baseado na despolimerização e, principalmente, na polarização de moléculas orgânicas, que passam a representar pequenos núcleos de floculação - a chamada "microfloculação". No entanto, segundo os autores, uma dosagem excessiva de ozônio pode causar uma fragmentação excessiva das moléculas, o que diminui o efeito da microfloculação. Assim deve-se buscar uma dosagem ótima para a otimização de tal fenômeno.

Em um trabalho sobre impactos causados pela ozonização em águas a serem potabilizadas, Singer (1989) comentou sobre a atuação do ozônio como auxiliar de coagulação e floculação. O autor relatou que seis em cada dez amostras examinadas em experimentos laboratoriais mostraram melhora na coagulação do material particulado após pré-ozonização, e afirmou ainda que "na maioria dos casos, as partículas suspensas tiveram sua carga negativa aumentada após préozonização, sugerindo que a coagulação induzida por ozônio no tratamento de águas não é um simples fenômeno eletrostático". De acordo com Langlais et al (1991), a ozonização promove a quebra de compostos orgânicos metálicos, com a subsequente liberação de íons metálicos oxidados, como o $\mathrm{Fe}^{+3}$ e o $\mathrm{Mn}^{+4}$, o que pode ser considerada uma produção de coagulantes "in situ". Os sais de ferro são amplamente utilizados como coagulantes primários e as espécies hidratadas de manganês podem remover quantidades significativas de MON por adsorção, especialmente na presença de cálcio. Além disso, os compostos orgânicos resultantes das reaçôes de quebra apresentam maior carga elétrica negativa resultante, o que os torna mais suscetíveis à adsorção por precipitados polares de hidróxido de alumínio, o que amplia a eficiência de remoção dos mesmos. Ainda segundo Langlais et al (1991), o ozônio também pode romper a superfície celular ou matar os vários tipos de algas, o que gera a liberação de biopolímeros (ácidos nucleicos, proteínas, polissacarídeos), e representa o aumento da presença de coagulantes orgânicos naturais. Segundo os autores, essa ação do ozônio sobre as algas representa efeito sobre a remoção de turbidez. Segundo Jekel (1994), os efeitos da ozonização sobre 
a coagulação, floculação ou outros processos de remoção de partículas são diversos, e que se espera que mais de um mecanismo básico seja operativo em desestabilização induzida por ozônio de partículas ou microfloculação de ozônio. Segundo o autor, "dois mecanismos básicos deveriam ser melhor compreendidos: a adsorção de matéria orgânica dissolvida no material particulado e os possíveis efeitos de polimerização de ozônio em baixas dosagens. Esses últimos podem explicar observações de vários pesquisadores, os quais reportaram a eficácia de dosagens bem baixas de ozônio (menores que $1,0 \mathrm{mg} / \mathrm{L}$ ) no tratamento de águas superficiais. Segundo Langlais (1997), os efeitos coagulantes do ozônio não são observados em todas as águas e não são perfeitamente compreendidos, mesmo que muitas explicações têm sido propostas; a aplicação de ozônio em uma determinada água deve ser criticamente avaliada, à luz de estudos pilotos.

Segundo Owen et al (1994), a pré-ozonização pode reduzir a dose de coagulante em meio ácido, pois pode aprimorar a remoção de MON. Por outro lado, segundo os autores, a ozonização tende a aumentar a fração hidrofílica da MON, com aumento da solubilidade da matéria orgânica e assim prejudicando as operações de coagulação e floculação da água no tocante à remoção de $\mathrm{MO}$, mas a remoção de turbidez (material particulado) pode melhorar. Ainda segundo os autores, outro possível impacto negativo é o aumento da demanda de cloro. Jekel (1994) apontou casos onde a pré-ozonização foi prejudicial à eficiência do tratamento, presumivelmente se a remoção de matéria orgânica dissolvida era prioritária, e não a remoção de partículas. No entanto, segundo o autor, uma avaliação global do processo de pré-ozonização indica que o mesmo pode ser positivo e ainda econômico em estaçóes de tratamento. Velásquez et al (1998) concluíram que o ozônio tem uma influência positiva no processo de coagulação-floculação quando aplicado em pequenas dosagens, típicamente da ordem de $1,0 \mathrm{mg} / \mathrm{L}$ ou menores. Segundo eles, "dosagens excessivas podem levar a uma deterioração da coagulação; os efeitos positivos do ozônio são relativos à diminuição da dosagem de coagulante inorgânico e à melhor remoção de sólidos e melhoria dos parâmetros físico-químicos".

A aplicação de ozonização na água decantada (ou inter-ozonização) pode levar a maiores eficiências de filtração na remoção de material particulado e MON dissolvida (West e Lage Filho, 1994; Camp, Dresser \& McKee, 1995a;1995b; Rittmann, 1996). West e Lage Filho (1994) verificaram em colunas de filtração feitas de acrílico transparente recebendo água decantada inter-ozonizada que os sólidos coletados pelos leitos filtrantes penetravam mais profundamente e apresentavam distribuição mais uniforme nos leitos do que na situação de filtração de água decantada sem inter-ozonização; o mesmo foi observado em estudo na SABESP (1998). A inter-ozonização também pode levar a carreiras de filtração mais longas, conforme observado por West e Lage Filho, 1994; Camp, Dresser \& McKee, 1995a; Smith et al, 1996. Segundo Wilczak et al (1992), "os efeitos da ozonização no desempenho de filtros ainda não estão bem documentados, mas em muitos casos foi detectado um aprimoramento da remoção de partículas na filtração de águas previamente ozonizadas, inclusive com a obtenção de um desempenho melhor do que em casos da utilização de um outro oxidante em lugar do ozônio". No entanto, tais benefícios da ozonização não são observados em todas as águas e, sendo assim, estudos piloto são altamente recomendáveis para avaliação de cada tipo de aplicação de ozônio para uma determinada água de interesse (Langlais, 1997; EPA, 1999; Montgomery Watson Harza, 2005).

Segundo West e Lage Filho (1994), quanto maiores os teores de COT na água bruta, maior a dificuldade em se obter remoções eficientes de sólidos suspensos a partir das operações unitárias de coagulação e floculação. Lage Filho et al (2001) obtiveram correlações muito boas entre valores pareados de turbidez e MO, absorbância UV254 e MO e entre cor aparente e $\mathrm{MO}$ (coeficientes de correlação $\mathrm{R}^{2}=0,86,0,90$ e 0,93, respectivamente), com implicações nas remoções de cor aparente e turbidez, em um estudo de tratabilidade da água bruta do rio Gravataí (água bruta com turbidez média 25 UNT, cor aparente média 295 un. Pt-Co, COT médio $10,0 \mathrm{mg} / \mathrm{L}$, absorbância média 0,76 e baixa alcalinidade, em torno de $20 \mathrm{mg} \mathrm{CaCO}_{3} / \mathrm{L}$ ).

A matéria orgânica na forma de COT é um dos principais responsáveis pela demanda de cloro (Becker, 1996). A demanda de cloro livre (DCL) é uma variável de qualidade da água associada à dosagem inicial de cloro livre, ao tempo de contato, à temperatura e ao $\mathrm{pH}$ da água (West e Lage Filho 1994). A demanda é o consumo de cloro livre por uma amostra, após o tempo de contato estipulado. $\mathrm{O}$ consumo de cloro pela água está associado às características físicas, químicas e biológicas, com destaque para a temperatura, turbidez, $\mathrm{pH}$, os teores de sólidos, íons metálicos e carbono orgânico total, a cor aparente, e concentrações de microrganismos tais como algas (representando MO). De acordo com West e Lage Filho (1994), para uma mesma temperatura e $\mathrm{pH}$ da água, há a tendência de que quanto maior a presença de matéria orgânica, maior a demanda de cloro livre e maior a geração de compostos indesejáveis formados em reaçóes com cloro, como por exemplo os compostos orgânicos clorados.

A remoção de sólidos e MON da água proporciona a redução do consumo de cloro aplicado para desinfecção final da água filtrada a ser enviada à rede de abastecimento (West e Lage Filho, 1994; American Water Works Association, 1999; Montgomery Watson Harza, 2005). Essa redução da DCL da água filtrada implica em diminuição da dosagem necessária de cloro livre, proporcionando diminuição da geração de sub-produtos de desinfecção e ainda contribuindo para a diminuição de problemas relativos à corrosão química na rede de distribuição (West e Lage Filho, 1994). Lage Filho e Botelho (2006) obtiveram uma boa correlação (coeficiente de correlação de 0,99 da curva de melhor ajuste dos dados) entre o teor de COT e a DCL de uma hora de contato da água filtrada, a partir de alguns ensaios de tratabilidade em escala piloto com água bruta do Reservatório do Guarapiranga.

Reduzir a demanda de cloro de uma água é um importante objetivo de qualidade. Reduzir a demanda significa reduzir o consumo de cloro pela água, implicando em poder reduzir a dosagem de cloro para desinfecção e outros fins, em uma menor geração de compostos orgânicos clorados e também implicando em menores custos de cloração.

Quanto menor for o intervalo de tempo entre a cloração da amostra e a determinação do residual, mais próxima será a demanda de cloro da chamada demanda imediata. A demanda imediata da água bruta pode ser uma espécie de "assinatura" da mesma; para uma água 
com pequenas variações em suas características ao longo do tempo, a demanda imediata parece apresentar variaçōes muito pequenas. $\mathrm{O}$ conhecimento da demanda imediata contribui para a caracterização da água e pode fornecer indicaçōes do potencial de formação de compostos orgânicos clorados (Camp, Dresser \& McKee, 1994).

Gráficos obtidos dos dados experimentais (mostrados na Tabela 2) de MO, abs UV 254, DCL e turbidez, são mostrados nas Figuras de 2 a 7.

Lage Filho et al (2001) obtiveram correlação com coeficiente $\mathrm{R}^{2}=0,90$ para águas filtradas do rio Gravataí, com coagulação com cloreto férrico e préozonização ou inter-ozonização prévia. A linha de tendência na Figura $2 \mathrm{com}$ equação: abs UV $254=0,0239(\mathrm{MO})$ - 0,0022 foi obtida para todos os dados de todas as etapas de tratamento $\left(\mathrm{R}^{2}=0,789\right)$. Para os dados dos três tratamentos com filtração (sem ozonização, com pré-ozonização ou inter-ozonização), os dois tratamentos com ozonização foram melhores na remoção de $\mathrm{MO}$ que o tratamento sem ozonização.

Há clara dispersão dos pontos na Figura 3; a DCL das águas decantada e bruta pré-ozonizada variou bastante com pequena variação de abs UV254 (10 a $20 \%)$. A pré-ozonização pode ter reduzido a abs UV254, mas parece não ter afetado a DCL. Para os três tratamentos com filtração (sem ozonização, com pré- ou inter-ozonização), o tratamento sem ozonização levou às maiores reduções da DCL. Estudos de tratabilidade de mananciais de qualidade (turbidez média abaixo de 0,7 UNT, COT abaixo de $2,0 \mathrm{mg} / \mathrm{L}$ ) não obtiveram redução da DCL em tratamento convencional com pré-ozonização (West e Lage Filho, 1994; Camp, Dresser \& McKee, 1995a; 1995b).

Há dispersão dos pontos na Figura 4. West e Lage Filho (1994) e Camp, Dresser \& McKee (1995b) não obtiveram correlação entre valores de DCL de 30 e 120 minutos de contato e os de COT para águas brutas e tratadas. Com relação aos três tipos de tratamentos com filtração (sem ozonização, com pré-ozonização ou inter-ozonização), o tratamento sem ozonização (3 pontos na Figura 4) apresentou relaçãoDCL/MO em torno de $0,7 \mathrm{mg} \mathrm{Cl} / \mathrm{mg} \mathrm{MO}$. Os tratamentos com pré-ozonização (3 pontos na Figura 4) e inter-ozonização (4 pontos

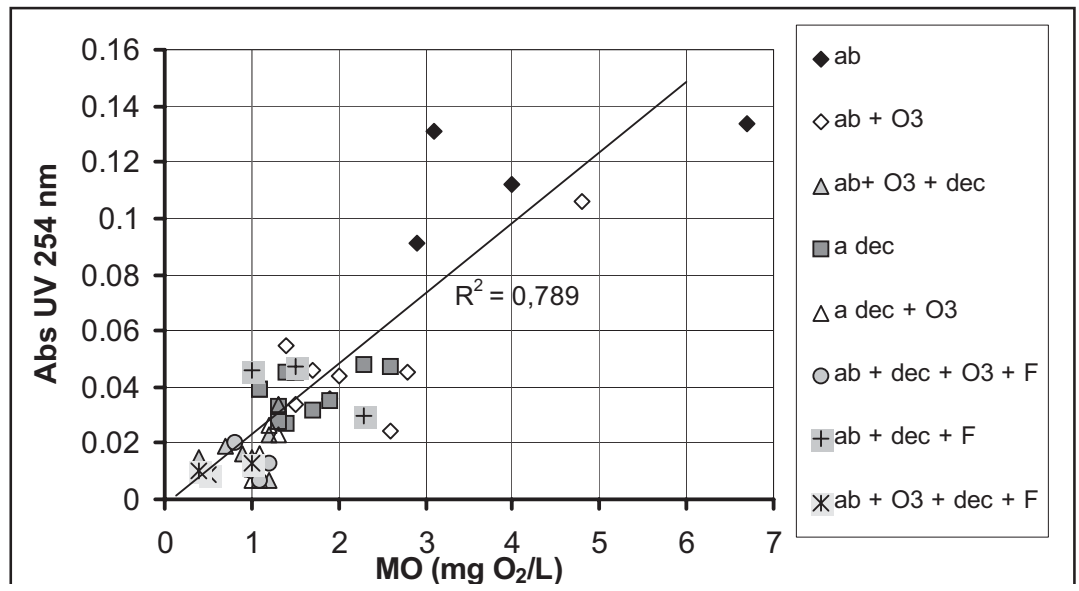

Figura 2 - Absorbância em luz UV 254 nm e teor de matéria orgânica (MO)

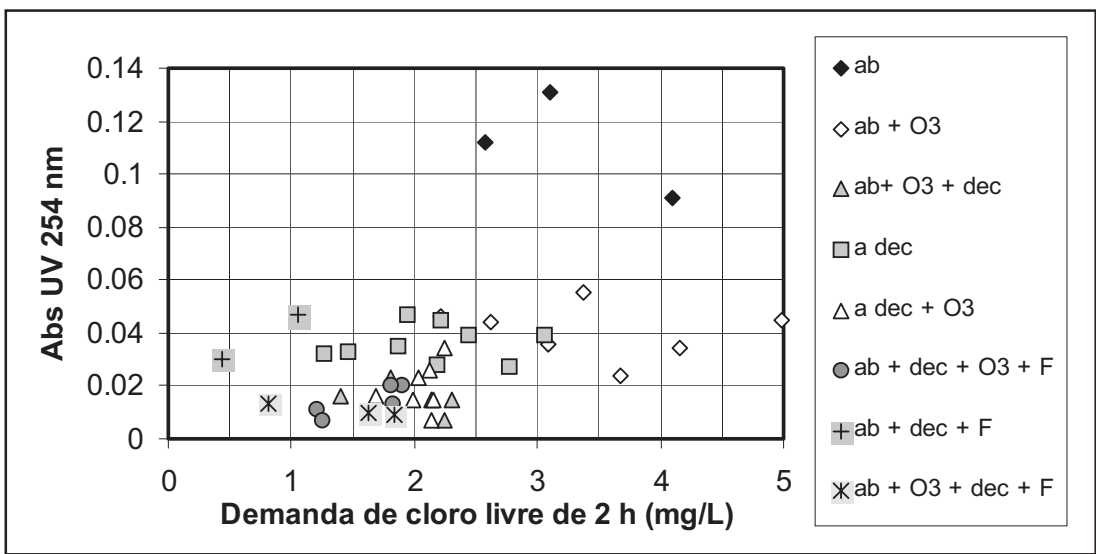

Figura 3 - Absorbância em luz UV 254 nm e demanda de cloro de 2 horas

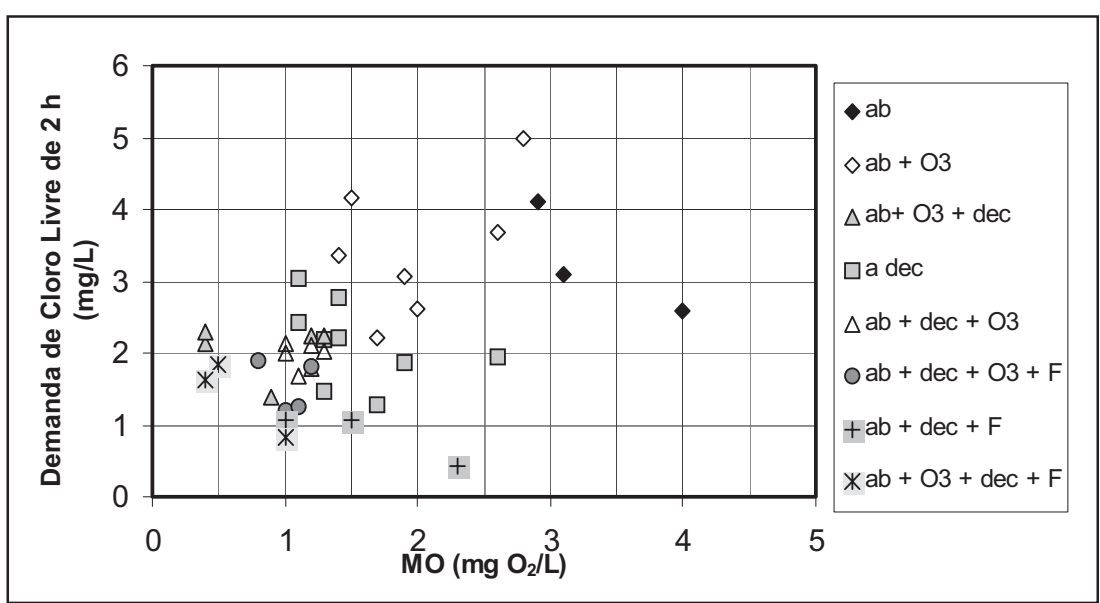

Figura 4 - Demanda de cloro de 2 horas e teor de matéria orgânica

na Figura 4) tiveram valores em torno de 2,7 e $1,6 \mathrm{mg} \mathrm{Cl}_{2} / \mathrm{mg} \mathrm{MO}$, respectivamente. A pré-ozonização parece ter reduzido a $\mathrm{MO}$ mas não a $\mathrm{DCL}$, em comparação com amostras de água bruta sem pré-ozonização.

Os pontos na Figura 5 mostram uma tendência de aumento da concentração de $\mathrm{MO}$ com o aumento na turbidez. Lage Filho et al (2001) obtiveram fraca correlação $\left(R^{2}=0,86\right)$ entre $\mathrm{MO}$ e turbidez para água tratada do rio Gravataí com pré-ozonização, coagulação-floculação com cloreto férrico $(\mathrm{pH}$ em torno de 6,0), decantação e filtração em carvão ativado ou antracito.

Na Figura 6 observa-se a tendência de um aumento em turbidez corres- 
ponder a aumento da abs UV254. A ozonização da água bruta reduziu a absorbância, o que foi notado nos vários estudos citados (West e Lage Filho, 1994; Camp, Dresser \& McKee, 1995a e 1995b; Lage Filho et al, 2001; Andrade Jr., 2004; Botelho, 2004; Lage Filho e Botelho, 2006).

Os dados experimentais mostrados na Figura 7 mostram a tendência de aumento da DCL com o aumento da turbidez. O gradiente de aumento da DCL com a turbidez foi inicialmente bastante elevado, para valores baixos de turbidez (até cerca de 0,5 UNT) e depois foi gradualmente apresentando uma tendência de curva assintótica. Tal mudança em comportamento dos dados experimentais pode ser explicada pela distribuiçãao granulométrica de partículas, que influencia a DCL e a turbidez da água. Águas de turbidez relativamente baixa apresentam distribuição granulométrica com grande predominância de partículas pequenas, tipicamente com tamanhos menores que $2 \mu \mathrm{m}$ e um número bem menor de partículas de tamanhos da ordem de dezenas de $\mu \mathrm{m}$ e maiores, enquanto que águas com turbidez relativamente alta apresentam um número bem maior de partículas com tamanhos da ordem de dezenas e centenas de $\mu \mathrm{m}$.

A variação do residual de cloro livre em água bruta do Reservatório do Guarapiranga em função da dose inicial de cloro livre (solução de hipoclorito de sódio com $1 \mathrm{mg}$ de cloro livre por $\mathrm{mL}$ de solução), para 2 horas e 10 minutos de tempo de contato, é mostrada na Figura 8. Os valores experimentais foram obtidos ao longo de vários meses de coleta de água bruta. A água bruta apresentou turbidez na faixa 3,0 a 4,3 UNT, cor aparente na faixa 40 a 56 un. Pt-Co, teor de matéria orgânica MO na faixa 2,9 a 6,7 $\mathrm{mg} \mathrm{O} / \mathrm{L}$, abs UV 254 na faixa 0,091 a 0,131 . Pela extrapolação das curvas para a situação de residual inicial zero, pode-se obter a chamada demanda imediata de cloro, que é característica intrínseca da água. Os coeficientes de correlação $\left(\mathrm{R}^{2}\right)$ das curvas de melhor ajuste foram 0,86 e 0,71 para os tempos de contato de 10 minutos e 2 horas, respectivamente. Quanto menor o tempo de contato, mais próximo do valor de demanda imediata deve ser o valor obtido de demanda. Sempre há incertezas experimentais; por exemplo, a volatilidade do cloro é um fator importante para

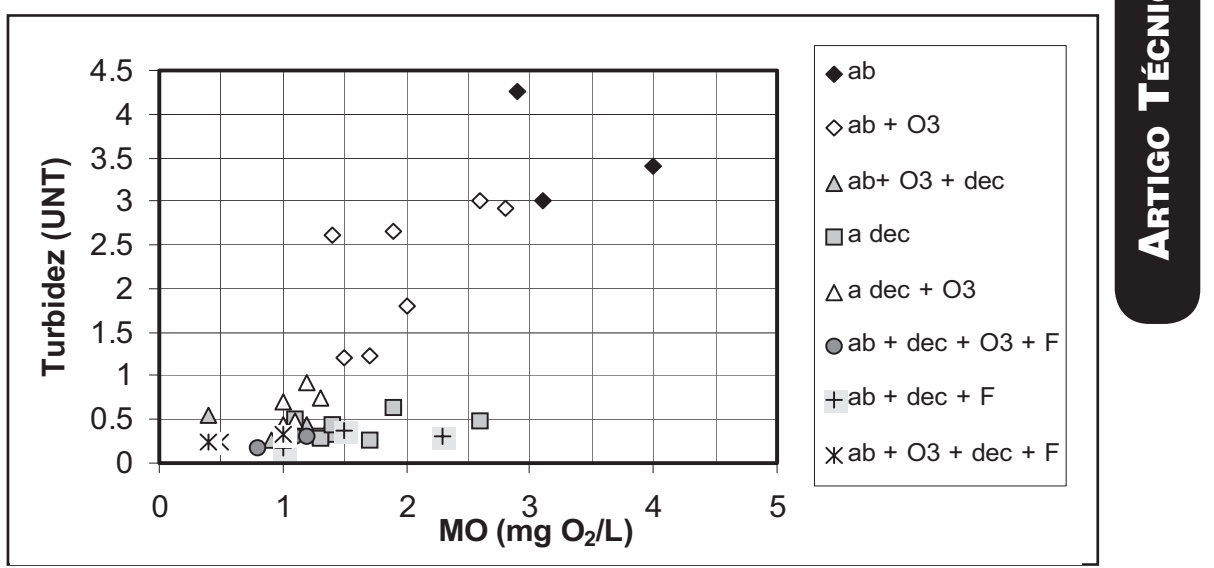

Figura 5 - Teor de matéria orgânica e turbidez das amostras

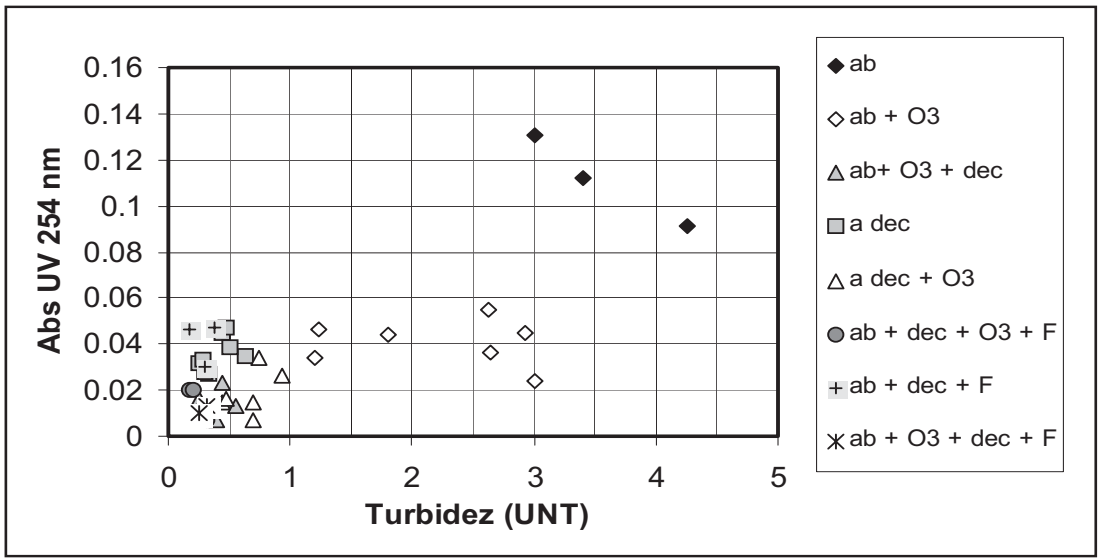

Figura 6 - Absorbância em luz UV 254 nm e turbidez

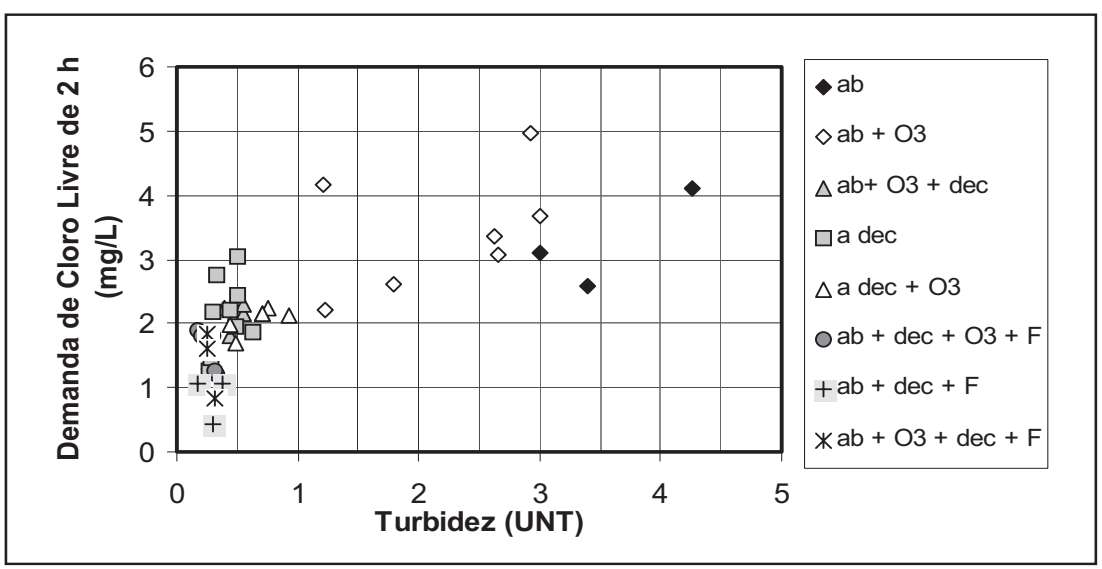

Figura 7 - Demanda de cloro de 2 horas e turbidez

explicar perdas do mesmo durante o tempo de espera (contato) e na determinação analítica. Segundo Gonçalves et al (2003), soluções de hipoclorito de cálcio apresentam perda de concentração de aproximadamente $0,013 \%$ por peso por dia, em temperatura ambiente. Segundo a Unites States Environmental Protection Agency (1986), a concentra- ção de uma solução de hipoclorito de sódio a $18 \%$ por peso em temperatura ambiente $\left(20\right.$ a $\left.25^{\circ} \mathrm{C}\right)$ reduz-se à metade em apenas 60 dias de estocagem, o que representa uma perda de concentração de $1,5 \mathrm{mg} / \mathrm{L}$ por dia ou cerca de $0,06 \mathrm{mg} / \mathrm{L}$ por hora.

Conforme indicado na Figura 8 , foram obtidos os valores de $0,4 \mathrm{e}$ 


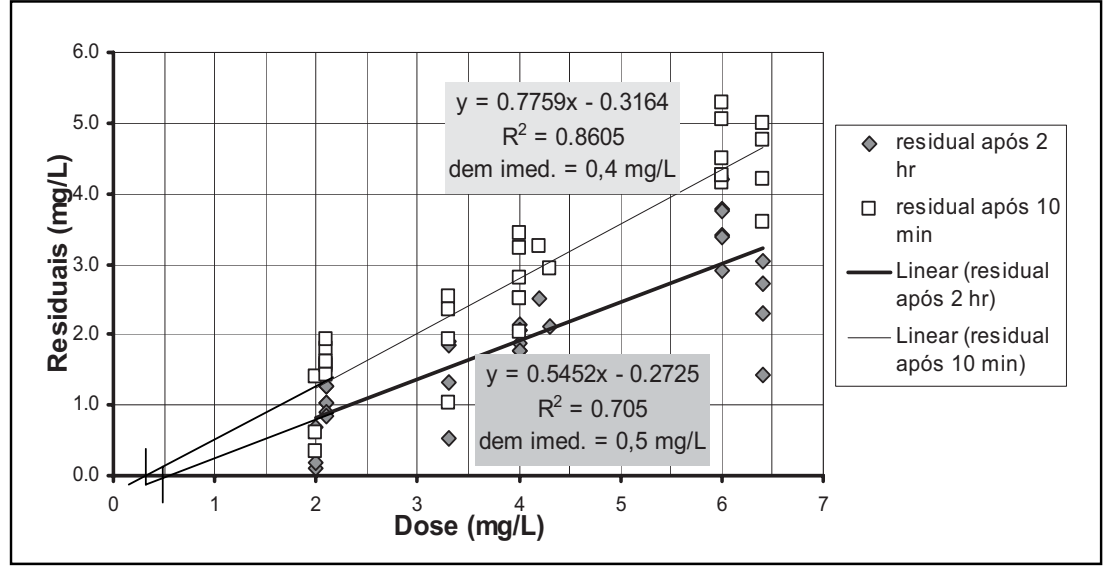

Figura 8 - Relações entre dose inicial e residuais de cloro livre pH na faixa 5,9 - 7,2 e temperatura da água na faixa 20 - $22{ }^{\circ} \mathrm{C}$

$0,5 \mathrm{mg} / \mathrm{L}$ para a demanda imediata de cloro da água bruta para $10 \mathrm{e}$ 120 minutos de tempo de contato, respectivamente. É provável que o valor da demanda imediata seja influenciado pela dose inicial de cloro; não se sabe se o $\mathrm{pH}$ pode influenciá-la. A demanda imediata pode ser um valor-referência valioso para avaliar: (a) o potencial de formação mínima de compostos orgânicos clorados na água bruta após pré-cloração ou na água filtrada após pós-cloração; (b) a dose mínima de cloro livre para controle biológico na água final, após desinfecção final. $\mathrm{O}$ conhecimento da demanda imediata de uma água decantada pode ainda ser útil para avaliar a dose mínima de cloro para uma inter-oxidação.

\section{CONCLUSÕES}

A análise dos resultados dos ensaios de tratabilidade com água bruta do Reservatório do Guarapiranga, com respeito aos parâmetros selecionados de qualidade, e para as operaçóes unitárias de tratamento relacionadas abaixo, permitiu concluir:

\section{(a) Decantação:}

- A pré-ozonização da água bruta levou a uma eficiência de remoção da MO maior do que a eficiência obtida pela inter-ozonização da água decantada, que por sua vez foi maior que a eficiência obtida pela decantação da água bruta sem ozonização. Em síntese, a ozonização (pré-ozonização ou inter-ozonização) favoreceu a remoção de $\mathrm{MO}$, em relação à ausência de ozonização.

- A pré-ozonização da água bruta ou a inter-ozonização da água decan- tada não pareceram influenciar a redução da DCL pela decantação simples (sem pré-ozonização da água bruta).

\section{(b) Filtração:}

- Os tratamentos com ozonização da água bruta ("pré-ozonização") ou ozonização da água decantada ("inter-ozonização") foram mais eficientes na remoção de $\mathrm{MO}$ do que o tratamento sem ozonização prévia.

- O tratamento sem ozonização foi mais eficiente na redução da DCL do que os tratamentos com ozonização (inter-ozonização da água decantada ou pré-ozonização da água bruta).

- Os tratamentos com ozonização conduziram à obtenção de valores da relação DCL/MO maiores do que os valores obtidos com tratamentos sem ozonização, indicando que a prática da pré-ozonização ou inter-ozonização levaram a uma maior demanda de cloro por unidade de concentração de $\mathrm{MO}$ do que os tratamentos sem ozonização.

\section{(c) Outras conclusões}

- A pré-ozonização reduziu valores de MO e de abs UV254 nm da água bruta.

- A DCL, abs UV254 e a concentração de $\mathrm{MO}$ tenderam a aumentar com o aumento da turbidez.

- O tempo de contato não pareceu influenciar o valor da demanda imediata.

\section{REFERÊNCIAS}

AMERICAN WATER WORKS ASSOCIATION. Guidance Manual on Alternative Disinfectants and Oxidants: Ozone, 96 pp.,1999.
ANDRADE JR., E. R. Efeitos da Ozonização sobre a Remoção de Matéria Orgânica Natural de Águas Eutrofizadas. Dissertação de Mestrado, Escola Politécnica da Universidade de São Paulo, 153 pp., 2004.

APHA, AWWA \& WEF: STANDARD METHODS FOR THE EXAMINATION OF WATER AND WASTEWATER. Clesceri, L. S.; Greenberg, A. E.; Eaton, A.D.,. 20a Edição, Washington-USA, 1998

BECKER, W. C.; O'MELIA, C. R. Optimizing Ozonation for Turbidity and Organics (TOC) Removal by Coagulation and Filtration. AWWA Research Foundation, Project Summary no 90703, dezembro de 1996.

BOTELHO, L. E. R. Efeitos da Pré-Ozonização como Auxiliar de Coagulação no Tratamento de Águas Eutrofizadas. Dissertação de Mestrado, Escola Politécnica da Universidade de São Paulo, 98 pp., 2004.

CAMP, DRESSER \& McKEE, INC. Balancing Multiple Water Quality Objectives - 4th Quarter Progress Report. American Water Works Association Research Foundation, 1994.

CAMP, DRESSER \& McKEE, INC. Water Quality Planning Study/Task 9 - Final Hetch Hetchy Treatability Report, 1995 a.

CAMP, DRESSER \& McKEE, INC. Water Quality Planning Study/Task 16 - Draft Sunol Treatability Report, $1995 \mathrm{~b}$.

ENVIRONMENTAL PROTECTION AGENCY. Guidance Manual for Compliance with the Interim Enhanced Surface Water Treatment Rule: Turbidity Provisions. Cincinatti, OH, USA, 272 pp., 1999.

FERREIRA FILHO, S. S.; MARCHETTO, M. Otimização Multi-Objetivo de Estações de Tratamento de Águas de Abastecimento: Remoção de Turbidez, Carbono Orgânico Total e Gosto e Odor. Revista Engenharia Sanitária e Ambiental, vol. 11, n.1, jan/mar 2006, pp. 7 - 15, 2006.

FRANCISCO JR; ORTH, P. D. Processo de Pré-Ozonização de Águas. Revista DAE, vol. 48, n. 152 , pp. $42-50$, jul/set. 1988 .

GONÇAVVES, R. F. (Coord.). Desinfecção de Efluentes Sanitários. Programa de Pesquisa em Saneamento Básico PROSAB, Edital 3, 422 pp., 2003.

HARZA, H. W. Water Treatment: Principles and Design. John Wiley \& Sons, Inc., 2a Edição, 1948 pp., 2005

JEKEL, M. R. Flocculation Effects of Ozone. Ozone Science \& Technology, vol. 16, pp. 55-66, 1994

LAGE FILHO, F. A. et al. Efeitos da Ozonização e Filtração com Carvão Ativado Granular na Remoção de Matéria Orgânica da Agua Bruta do Rio Gravatai, RS. In: 21 CONGRESSO DA ASSOCIAÇÃO BRASILEIRA DE ENGENHARIA SANITÁRIA ABES, vol. 2, pp. 190 - 204. João Pessoa, PB, 2001.

LAGE FILHO, F. A., BOTELHO, L. E. R. Avaliação Preliminar do Efeito de Combinaçôes de Coagulantes e do Tipo de Meio Filtrante na Remoção de COT e na Demanda de Cloro da Água Filtrada. Trabalho aceito para publicação na Revista Sanare da SANEPAR - Paraná, 9 pp., 2006.

LANGLAIS, B. Overview of the Use of Ozone for Drinking Water. International Symposium: Use of 
Ozone for Water Treatment, Nizhny Novgorod, Sept. 15-16, 1997.

LANGLAIS, B.; RECKHOW, D. A.; BRINK, D. R. Ozone in Water Treatment: Application and Engineering. Lewis Publishers, 789 pp., 1991.

OWEN, D. M.; BRENNAN, W. J.; CHOWDHURY, Z. K. Practical Implications of Enhanced Coagulation. ANAIS DA AWWA WATER QUALITY TECHNOLOGY CONFERENCE, San Francisco, CA, USA pp. $31-47,1994$.

PENITSKY, D. J. Coagulation 101. Em: Proceedings, Technology Transfer Conference, Universidade de Calgary, Alberta, Canadá, 2003.

RITTMANN, B. E. Back to Bacteria: A More Natural Filtration. Civil Engineering, vol. 7, pp. $50-52,1996$.

SABESP - COMPANHIA ESTADUAL DE SANEAMENTO E ABASTECIMENTO DE ÁGUA. Filtros Adsorvedores de Carvão Ativado Granular para a Remoção de Compostos Causadores de Gosto e Odor. Relatório da Camp, Dresser \& McKee, Sistema Guarapiranga, SABESP, 122 pp., 1998.

SABESP - COMPANHIA ESTADUAL DE SANEAMENTO E ABASTECIMENTO DE ÁGUA: Informaçôes Gerais sobre o Sistema Guarapiranga. Disponível em http://www.sabesp.com. br. Acesso em 30/05/2003.
SINGER, P.C. Impact of Ozone on the Removal of Particles, TOC and THM Precursors. AWWA Reserach Foundation, Research Summary n. 6,1989 .

SINGER, P. C.; HARRINGTON, G. W. Coagulation of DBP Precursors: Theoretical and Practical Considerations. Em: Anais da AWWA Water Quality Technology Conference, Austin, TX, USA, 1993.

SMITH, D. J.; PETTIT, P.; SCHOFIELD, T. Activated Carbon in Water Treatment. Water Supply, vol. 14 , n. 2, pp. 85 - 98. Blackwell Science Ltd., Amsterdam (1996).

USEPA - UNITEDSTATES ENVIRONMENTAL PROTECTION AGENCY. Municipal Wastewater Disinfection. Design Manual EPA/625/1-86/021. Cincinatti, Ohio, 247 pp., 1986.

VELÁSQUEZ, M. T. O.; et al. Improvement of Water Coagulation Using Ozone. Ozone Science \& Engineering, vol. 20, pp. 151-162, 1998.

WEST, T. E.; LAGE FILHO, F. A. Hetch Hetchy Treatability Report. Relatório preparado para Camp, Dresser \& McKee Consulting Engineers, Walnut Creek, CA, USA, 432 pp., 1994.

WILCZAK, A.; et al. How Preoxidation Affects Particle Removal During Clarification and Filtration. Journal AWWA, vol. 84, n. 12, pp. $85-94,1992$.
Endereço para correspondência:

Frederico de Almeida Lage Filho Escola Politécnica da USP Departamento de Engenharia Hidráulica e Sanitária Av. Prof. Almeida Prado, Travessa 2, n. 27 I - Prédio da Engenharia Civil. Cidade Universitária 05508-900 São Paulo - SP - Brasil

Tel. (II) 309 I-5327 - 309 I-5529

Fax (II) 309I-5423

E-mail: fredlage@usp.br 